\title{
Pediatric oncofertility: an update
}

\author{
Glen A. Lau, Anthony J. Schaeffer \\ Division of Urology, University of Utah, Salt Lake City, UT, USA \\ Contributions: (I) Conception and design: All authors; (II) Administrative support: None; (III) Provision of study materials or patients: None; (IV) \\ Collection and assembly of data: All authors; (V) Data analysis and interpretation: All authors; (VI) Manuscript writing: All authors; (VII) Final \\ approval of manuscript: All authors. \\ Correspondence to: Glen A. Lau, MD. Division of Urology, University of Utah, Salt Lake City, UT, USA. Email: glen.Lau@hsc.utah.edu.
}

\begin{abstract}
Fertility preservation (FP) in pediatric patients with cancer is an evolving field. In this review, we give a short update on recent scientific advances in the practice of pediatric oncofertility, particularly related to the research involving gonadal tissue cryopreservation from prepubertal patients, which remains experimental. We then focus on recent advances in the implementation of formal pediatric oncofertility programs and barriers in the delivery of FP in this patient population. Finally, we include some of the more recent outcomes data from established oncofertility programs that treat pediatric patients.
\end{abstract}

Keywords: Pediatric; fertility; preservation; oncofertility; cancer

Submitted Nov 19, 2019. Accepted for publication Jul 11, 2020.

doi: 10.21037/tau-20-991

View this article at: http://dx.doi.org/10.21037/tau-20-991

\section{Introduction}

Oncofertility is a relatively young field (1) that is meant to address the potential detrimental effects that cancer treatment can have on future fertility. The field of pediatric oncofertility, or fertility preservation (FP) in children with a diagnosis of cancer, brings with it multiple layers of added complexity not present when treating adults (2). Issues of consent, equity and other ethical pitfalls exist.

Childhood cancers vary widely in treatment and outcomes, but overall survival based on contemporary estimates is over $80 \%$ (3). This leaves a large number of patients who survive into adulthood and are subject to the long-term morbidities of cancer treatment, with recent estimates putting that number at close to 400,000 in the United States alone (3). One major long-term effect of cancer treatment is infertility, which is due to the relative susceptibility of the gonads to the detrimental effects of these treatments. Based on data from the Childhood Cancer Survivor Study cohort, males are at higher relative risk of infertility than their female counterparts $(2.6 \mathrm{vs}$. 1.3, respectively) $(4,5)$, however both show significantly lower rates of fertility than sibling controls $(5,6)$.
Infertility can be a result of a number of different cancer treatments. This includes chemotherapy, particularly with alkylating agents $(7,8)$ and heavy metals (9). Radiation, either directly to the gonads $(10,11)$, or indirectly through damaging the hypothalamic and pituitary secretion of gonadotropins from the brain (12) have also been shown to have dose-dependent effects on fertility in the long term. Management of some cancers also involves surgical removal of reproductive organs, also leading to direct effects on fertility (13).

Due to the risk of infertility, particularly with higher risk patients, preserving sex cells or gonadal tissue for future use in fertility treatments is an accepted practice with guidelines suggesting referral for these services to all post-pubertal patients, both male and female (14). We recently published a review of contemporary advancements in the field of pediatric oncofertility (15). In this article, we will review the scope of the problem and provide a brief update on the science of pediatric FP, but also aim to focus on and provide an update on recent advances in the delivery of oncofertility care to the pediatric population, which is the focus of much of the literature since our last publication. 


\section{Pediatric FP: where is the science?}

Currently, there are established protocols that have resulted in live births using gonadal tissue or sex cells obtained from post-pubertal patients prior to initiation of gonadotoxic treatment of cancers (16-18). There has also been a case report of a successful pregnancy and live birth in a patient who had primary ovarian failure using retransplanted, cryopreserved, autologous ovarian tissue collected prior to menarche (19). A mature oocyte has also been obtained from xenotransplanted, cryopreserved ovarian tissue obtained from a 6-year-old female prior to her undergoing gonadotoxic chemotherapy (20). With these promising experimental results, there appears to be hope for eventual clinical success of FP in pre-pubertal females in the near future (21).

In the case of pre-pubertal males, however, success continues to be limited. To date, there has not been successful maturation of spermatogonial stem cells from pre-pubertal human tissue beyond the diploid phase using autotransplantation or xenotransplantation (22), although complete maturation has been achieved using xenotransplanted primate testicular tissue $(23,24)$. While promising, xenotransplantation in both male and female human patients is thought to be less acceptable as it can have unknown effects on human cells (25).

In vitro maturation of stem cells from pre-pubertal testicular tissue is a strategy that is also being investigated. While there has been no success in differentiating stem cells into mature sperm, de Michele et al. have been able to obtain haploid cells from long-term culture of frozenthawed pre-pubertal human testis tissue, suggesting that this approach may eventually lead to successful fertility outcomes $(26,27)$.

Given the rapid advances in the field, studies from both the United States and Europe have shown that cryopreservation of pre-pubertal testicular tissue is acceptable to the majority of parents for the possibility of FP in the future (28-30). The most recent guidelines, however, continue to consider the collection of this tissue experimental and thus only recommend the practice in conjunction with an established research protocol (14).

\section{Delivery of FP care}

As the science advances, the clinical delivery of FP services must also progress. While there are well thought out guidelines for FP in adult patients (31) there are multiple additional complexities for pediatric patients that must be considered. Despite this, recommendations for the discussion of FP options with families of patients with a new diagnosis of childhood cancer have existed for over a decade (32). Where these recommendations do exist, implementation seems to be less straightforward. FP is often not discussed in clinical interactions with families, which can lead to disappointment and regret from some patients (33). A survey of providers in Sweden showed that of the responding physicians (all of whom were involved in pediatric oncology care), the potential impact of cancer care on fertility was only discussed with $62 \%$ of male patients and $57 \%$ of female patients (34), where more recent estimates suggest that rates may be much less than this (35).

Even patients within an established network of centers that offer tissue cryopreservation, 39\% of samples were collected from patients that had already initiated gonadotoxic treatment (36), suggesting that there is often a delay in consultation. These findings underscore the importance of having an organized way of identifying, referring and counselling these patients to allow timely care.

In order for this to occur, there should be an organized way for these services to be offered and performed. This can be challenging because it necessitates the involvement and coordination of multiple providers and specialties. Moravek et al. describe the formation of a pediatric oncofertility program and its ideal elements (13). These elements include a program director and an administrative coordinator. Along with central administration, there must be coverage by medical and surgical specialties including pediatric oncology and endocrinology, pediatric surgery, pediatric urology and pediatric/adolescent gynecology. While medical and surgical specialties are integral in the initial consultation and subsequent surgical management of $\mathrm{FP}$, having a pathology team that is experienced in FP techniques is essential in a successful program. Proper processing and storage can also involve adult infertility specialists and facilities that coordinate with pediatric providers. While there is even a textbook chapter dedicated to setting up this type of program in the pediatric setting (37), navigating the referral patterns, interdepartmental relationships, insurance concerns and other challenges requires an individualized workflow for each participating center (38).

Other supportive services that can also be extremely valuable in appropriate delivery of pediatric oncofertility care include social work and behavioral/mental health participation. These vital ancillary services can assist with the logistical and financial concerns along with 
the psychosocial stress of the potential of infertility that accompanies a diagnosis of childhood cancer (13).

Another element of appropriate delivery of care is the development of evidence-based patient education materials and decision aids (39). These can assist in standardizing the information that is given to patients and parents, which improves understanding of the options and confidence in decision-making (40). Publicly available resources do exist, but not all are specific to the pediatric population $(41,42)$.

With these recommendations, barriers remain in the implementation of successful delivery of pediatric FP. In a systematic review by Anazodo et al. (43), the literature regarding models of care (MOC) for pediatric oncofertility was reviewed and themes were identified to suggest major areas of improvement in the delivery of care. Their group identified the following nine domains of oncofertility MOCs (a number of which have already been discussed):

(I) Communication;

(II) Oncofertility decision aids;

(III) Provision of care, including age appropriate care;

(IV) Referral pathways between cancer and FP services;

(V) Documentation of oncofertility discussions, decisions and procedures;

(VI) Training of cancer and fertility healthcare professionals (HCPs) to deliver oncofertility care;

(VII) Medical supportive care during FP;

(VIII) Reproductive care in survivorship;

(IX) Fertility-related psychosocial support.

Within the nine domains of oncofertility MOCs, the major areas of improvement that were identified included the importance of providing high quality information across a variety of different formats (including decision aids) to patients, assuring care is delivered in a prompt manner, assuring age-appropriate consultation and recommendations, better defining the roles of practitioners within the care model, and assuring adequate communication and coordination between the various professionals involved in pediatric oncofertility care.

Although these areas do not address all of the barriers to delivering pediatric oncofertility care, they do highlight a number of areas where the literature has not provided consistent solutions and recommendations in the form of guidelines.

\section{Contemporary outcomes}

There is abundant literature on establishing and implementing a pediatric oncofertility program, but there remains a lack of information on the effects that a formal pediatric oncofertility program can have on patient satisfaction and utilization of FP. In fact, no pediatricspecific literature has been published to date. At this point, information that is "pediatric-specific" must be extrapolated from programs that include both adolescents and young adults (AYA). With regard to patient satisfaction, Kelvin et al. showed an increase in satisfaction with the resources and amount of information provided that was significant regardless of gender or diagnosis after establishment of their oncofertility program (44). In the same study, $96 \%$ of males and $99 \%$ of females who received and read informational materials in the program considered them to be helpful.

The effect of establishing a dedicated AYA oncofertility program has similarly been shown to affect utilization of FP services. In a study from Canada, Lewin et al. reported that after establishment of their oncofertility program geared toward AYA, both documentation of infertility risk discussion and utilization of $\mathrm{FP}$ increased from approximately $55 \%$ to $85 \%$ (45). Lopategui et al. from the United States described outcomes of their formal oncofertility program that did include a minority of pediatric patients (46). During the first year of their program, the percentage of oncology patients undergoing FP increased over 6-fold to $19.3 \%$ compared to $3.3 \%$ in the 5 years prior to the establishment of the program. There is a large disparity in the numbers reported by these different institutions (likely reflecting differences in coverage of these services in different countries), but they both show a substantial increase in utilization after establishment of a formal oncofertility program. This underscores the importance of these programs in increasing access to these services in the pediatric population.

Another area that has been investigated with regard to pediatric oncofertility are the awareness, perceptions and attitudes of adult survivors of childhood cancer toward potential infertility (47). In a study from the St. Jude survivorship cohort, Lehman et al. reported that while most childhood cancer survivors $(61.9 \%)$ perceived themselves at increased risk for infertility, laboratoryevaluated impaired gonadal function was found in $24.3 \%$ of female and $55.6 \%$ of male survivors. Concordance with laboratory-demonstrated subfertility was low (Cohen's $<0.19$ ) with $19.7 \%$ of male and $43.6 \%$ of female survivors overestimating their risk and a significant number of male $(16.3 \%)$ and female $(5.3 \%)$ survivors who underestimated their risk of infertility (48).

Using a different cohort from Nationwide Children's 
Hospital (49), Lehman demonstrated again that the majority of patients in that cohort were aware of an increased risk of infertility $(82.4 \%)$ from childhood cancer treatments, but $48.9 \%$ had never been tested and did not know their fertility status. Ten percent of patients in that study claimed that infertility had negatively impacted their relationships, which was mainly found in partnered survivors who had no children or desired additional children. While this is the case, there is evidence that those individuals who undergo proper referrals and opt for oncofertility care are typically those that would benefit from it the most. A study from the Oncofertility Consortium's National Physicians Cooperative evaluating 114 female patients who underwent ovarian tissue cryopreservation showed that those opting for this treatment were predominantly patients with leukemias, myeloproliferative and myelodysplastic diseases, malignant bone tumors and soft tissue sarcomas (50). This group of patients had the highest overall risk of infertility in the cohort and were, thus, the most likely to benefit from FP techniques.

These studies not only underscore the importance of early FP discussion and treatments in the pediatric period, but also highlight the need for accurate, personalized prognostic information to aid in decision making. They also show the importance of long-term follow-up and discussion with survivors, as the information that is initially shared with parents is often not carried with the patient into adulthood. Because of this, the authors recommend that fertility testing and treatment should be routinely offered as patient circumstances and interest in fertility can change and evolve over time (49). These further encounters may best be had by adult reproductive endocrinology and andrology specialists, which can be a part of the pediatric oncofertility team (13). FP offered in the pediatric period would potentially keep options open as these patients reach an age when fertility becomes a concern.

\section{Conclusions}

Pediatric oncofertility remains a developing field with significant challenges and imperfect solutions. Current literature emphasizes a focus on improving the delivery of this care to appropriate pediatric cancer patients and advancing the science to extend fertility options to prepubertal patients. While further research is needed in both of these areas, survivorship studies show that these continued efforts can have a positive impact on an everincreasing number of patients.

\section{Acknowledgments}

Funding: Dr. Schaeffer is supported by NIH/NIDDK K08DK119535.

\section{Footnote}

Provenance and Peer Review: This article was commissioned by the Guest Editors (John Wiener, Jonathan Routh and Nicholas Cost) for the series "Pediatric Urologic Malignancies" published in Translational Andrology and Urology. The article was sent for external peer review organized by the Guest Editors and the editorial office.

Conflicts of Interest: Both authors have completed the ICMJE uniform disclosure form (available at http://dx.doi. org/10.21037/tau-20-991). The series "Pediatric Urologic Malignancies" was commissioned by the editorial office without any funding or sponsorship. Both authors have no other conflicts of interest to declare.

Ethical Statement: The authors are accountable for all aspects of the work in ensuring that questions related to the accuracy or integrity of any part of the work are appropriately investigated and resolved.

Open Access Statement: This is an Open Access article distributed in accordance with the Creative Commons Attribution-NonCommercial-NoDerivs 4.0 International License (CC BY-NC-ND 4.0), which permits the noncommercial replication and distribution of the article with the strict proviso that no changes or edits are made and the original work is properly cited (including links to both the formal publication through the relevant DOI and the license). See: https://creativecommons.org/licenses/by-nc-nd/4.0/.

\section{References}

1. Lee SJ, Schover LR, Partridge AH, et al. American Society of Clinical Oncology recommendations on fertility preservation in cancer patients. J Clin Oncol 2006;24:2917-31.

2. Johnson EK, Finlayson C, Rowell EE, et al. Fertility Preservation for Pediatric Patients: Current State and Future Possibilities. J Urol 2017;198:186-94.

3. Phillips SM, Padgett LS, Leisenring WM, et al. Survivors of childhood cancer in the United States: prevalence and burden of morbidity. Cancer Epidemiol Biomarkers Prev 
2015;24:653-63.

4. Wasilewski-Masker K, Seidel KD, Leisenring W, et al. Male infertility in long-term survivors of pediatric cancer: a report from the childhood cancer survivor study. J Cancer Surviv 2014;8:437-47.

5. Barton SE, Najita JS, Ginsburg ES, et al. Infertility, infertility treatment, and achievement of pregnancy in female survivors of childhood cancer: a report from the Childhood Cancer Survivor Study cohort. Lancet Oncol 2013;14:873-81.

6. Green DM, Kawashima T, Stovall M, et al. Fertility of male survivors of childhood cancer: a report from the Childhood Cancer Survivor Study. J Clin Oncol 2010;28:332-9.

7. Chemaitilly W, Li Z, Krasin MJ, et al. Premature Ovarian Insufficiency in Childhood Cancer Survivors: A Report From the St. Jude Lifetime Cohort. J Clin Endocrinol Metab 2017;102:2242-50.

8. Green DM, Liu W, Kutteh WH, et al. Cumulative alkylating agent exposure and semen parameters in adult survivors of childhood cancer: a report from the St Jude Lifetime Cohort Study. Lancet Oncol 2014;15:1215-23.

9. Chow EJ, Stratton KL, Leisenring WM, et al. Pregnancy after chemotherapy in male and female survivors of childhood cancer treated between 1970 and 1999: a report from the Childhood Cancer Survivor Study cohort. Lancet Oncol 2016;17:567-76.

10. Meistrich ML. Male gonadal toxicity. Pediatr Blood Cancer 2009;53:261-6.

11. Wallace $\mathrm{WH}$, Thomson AB, Saran F, et al. Predicting age of ovarian failure after radiation to a field that includes the ovaries. Int J Radiat Oncol Biol Phys 2005;62:738-44.

12. Darzy KH, Shalet SM. Hypopituitarism following Radiotherapy Revisited. Endocr Dev 2009;15:1-24.

13. Moravek MB, Appiah LC, Anazodo A, et al. Development of a Pediatric Fertility Preservation Program: A Report From the Pediatric Initiative Network of the Oncofertility Consortium. J Adolesc Health 2019;64:563-73.

14. Oktay K, Harvey BE, Loren AW. Fertility Preservation in Patients With Cancer: ASCO Clinical Practice Guideline Update Summary. J Oncol Pract 2018;14:381-5.

15. Lau GA, Schaeffer AJ. Current standing and future directions in pediatric oncofertility: a narrative review. Transl Androl Urol 2018;7:S276-S282.

16. Bunge RG, Sherman JK. Fertilizing capacity of frozen human spermatozoa. Nature 1953;172:767-8.

17. Konc J, Kanyo K, Kriston R, et al. Cryopreservation of embryos and oocytes in human assisted reproduction.
Biomed Res Int 2014;2014:307268.

18. Jensen AK, Macklon KT, Fedder J, et al. 86 successful births and 9 ongoing pregnancies worldwide in women transplanted with frozen-thawed ovarian tissue: focus on birth and perinatal outcome in 40 of these children. J Assist Reprod Genet 2017;34:325-36.

19. Demeestere I, Simon P, Dedeken L, et al. Live birth after autograft of ovarian tissue cryopreserved during childhood. Hum Reprod 2015;30:2107-9.

20. Raffel N, Lotz L, Hoffmann I, et al. Repetitive Maturation of Oocytes From Non-Stimulated Xenografted Ovarian Tissue From a Prepubertal Patient Indicating the Independence of Human Ovarian Tissue. Geburtshilfe Frauenheilkd 2017;77:1304-11.

21. Dinikina Y, Belogurova M, Zaritskey A, et al. Ovarian tissue cryopreservation in prepubertal patients with oncological diseases: multidisciplinary approach and outcomes. J Matern Fetal Neonatal Med 2019. doi: 10.1080/14767058.2019.1666364.

22. Del Vento F, Vermeulen M, de Michele F, et al. Tissue Engineering to Improve Immature Testicular Tissue and Cell Transplantation Outcomes: One Step Closer to Fertility Restoration for Prepubertal Boys Exposed to Gonadotoxic Treatments. Int J Mol Sci 2018;19:286.

23. Ntemou E, Kadam P, Van Saen D, et al. Complete spermatogenesis in intratesticular testis tissue xenotransplants from immature non-human primate. Hum Reprod 2019;34:403-13.

24. Fayomi AP, Peters K, Sukhwani M, et al. Autologous grafting of cryopreserved prepubertal rhesus testis produces sperm and offspring. Science 2019;363:1314-9.

25. Kimsa MC, Strzalka-Mrozik B, Kimsa MW, et al. Porcine endogenous retroviruses in xenotransplantation--molecular aspects. Viruses 2014;6:2062-83.

26. de Michele F, Poels J, Vermeulen M, et al. Haploid Germ Cells Generated in Organotypic Culture of Testicular Tissue From Prepubertal Boys. Front Physiol 2018;9:1413.

27. Portela JMD, de Winter-Korver CM, van Daalen SKM, et al. Assessment of fresh and cryopreserved testicular tissues from (pre)pubertal boys during organ culture as a strategy for in vitro spermatogenesis. Hum Reprod 2019;34:2443-55.

28. Wyns C, Collienne C, Shenfield F, et al. Fertility preservation in the male pediatric population: factors influencing the decision of parents and children. Hum Reprod 2015;30:2022-30.

29. Ginsberg JP, Li Y, Carlson CA, et al. Testicular tissue cryopreservation in prepubertal male children: an analysis 
of parental decision-making. Pediatr Blood Cancer 2014;61:1673-8.

30. van den Berg H, Repping S, van der Veen F. Parental desire and acceptability of spermatogonial stem cell cryopreservation in boys with cancer. Hum Reprod 2007;22:594-7.

31. Anazodo A, Laws P, Logan S, et al. The Development of an International Oncofertility Competency Framework: A Model to Increase Oncofertility Implementation. Oncologist 2019;24:e1450-9.

32. Fallat ME, Hutter J. Preservation of fertility in pediatric and adolescent patients with cancer. Pediatrics 2008; 121:e1461-9.

33. Jayasuriya S, Peate M, Allingham C, et al. Satisfaction, disappointment and regret surrounding fertility preservation decisions in the paediatric and adolescent cancer population. J Assist Reprod Genet 2019;36:1805-22.

34. Armuand GM, Nilsson J, Rodriguez-Wallberg KA, et al. Physicians' self-reported practice behaviour regarding fertility-related discussions in paediatric oncology in Sweden. Psychooncology 2017;26:1684-90.

35. Mobley EM, Ryan GL, Sparks AE, et al. Factors Impacting Fertility Preservation in Adolescents and Young Adults with Cancer: A Retrospective Study. J Adolesc Young Adult Oncol 2020;9:208-21.

36. Valli-Pulaski H, Peters KA, Gassei K, et al. Testicular tissue cryopreservation: 8 years of experience from a coordinated network of academic centers. Hum Reprod 2019;34:966-77.

37. Burns K, Breech L. Setting Up a Pediatric Oncofertility Practice. In: Woodruff TK, Gosiengfiao YC. editors. Pediatric and Adolescent Oncofertility: Best Practices and Emerging Technologies. Cham: Springer International Publishing; 2017:231-41.

38. Coccia PF, Altman J, Bhatia S, et al. Adolescent and young adult oncology. Clinical practice guidelines in oncology. $\mathrm{J}$ Natl Compr Canc Netw 2012;10:1112-50.

39. Jones G, Hughes J, Mahmoodi N, et al. What factors hinder the decision-making process for women with cancer and contemplating fertility preservation treatment? Hum Reprod Update 2017;23:433-57.

Cite this article as: Lau GA, Schaeffer AJ. Pediatric oncofertility: an update. Transl Androl Urol 2020;9(5):2416-2421. doi:10.21037/tau-20-991
40. Stacey D, Legare F, Lewis K, et al. Decision aids for people facing health treatment or screening decisions. Cochrane Database Syst Rev 2017;4:CD001431.

41. Northwestern University TOC. Save my fertility 2017. Available online: https://www.savemyfertility.org/

42. Children's C. Comprehensive Fertility Care \& Preservation Program (CFCPP) 2017. Available online: https://www.cincinnatichildrens.org/service/f/fertilitypreservation

43. Anazodo A, Laws P, Logan S, et al. How can we improve oncofertility care for patients? A systematic scoping review of current international practice and models of care. Hum Reprod Update 2019;25:159-79.

44. Kelvin JF, Thom B, Benedict C, et al. Cancer and Fertility Program Improves Patient Satisfaction With Information Received. J Clin Oncol 2016;34:1780-6.

45. Lewin J, Ma JMZ, Mitchell L, et al. The positive effect of a dedicated adolescent and young adult fertility program on the rates of documentation of therapy-associated infertility risk and fertility preservation options. Support Care Cancer 2017;25:1915-22.

46. Lopategui DM, Ibrahim E, Aballa TC, et al. Effect of a formal oncofertility program on fertility preservation ratesfirst year experience. Transl Androl Urol 2018;7:S271-5.

47. Stein DM, Victorson DE, Choy JT, et al. Fertility Preservation Preferences and Perspectives Among Adult Male Survivors of Pediatric Cancer and Their Parents. J Adolesc Young Adult Oncol 2014;3:75-82.

48. Lehmann V, Chemaitilly W, Lu L, et al. Gonadal Functioning and Perceptions of Infertility Risk Among Adult Survivors of Childhood Cancer: A Report From the St Jude Lifetime Cohort Study. J Clin Oncol 2019;37:893-902.

49. Lehmann V, Nahata L, Ferrante AC, et al. FertilityRelated Perceptions and Impact on Romantic Relationships Among Adult Survivors of Childhood Cancer. J Adolesc Young Adult Oncol 2018;7:409-14.

50. Armstrong AG, Kimler BF, Smith BM, et al. Ovarian tissue cryopreservation in young females through the Oncofertility Consortium's National Physicians Cooperative. Future Oncol 2018;14:363-78. 